\title{
Avaliação da qualidade da água para irrigação dos açudes urbanos do município de Angicos-RN
}

\author{
Assessment of water quality for irrigation \\ of urban dams in the municipality of Angicos-RN
}

Francisco Souto de Sousa Júnior ${ }^{1 *}$, Pedro Carlos Costa Silva ${ }^{1}$

\begin{abstract}
RESUMO
O município de Angicos está localizado na região semiárida do nordeste brasileiro, onde as condições climáticas provocam a escassez. Dessa forma, este trabalho tem como objetivo avaliar a qualidade da água para irrigação dos três açudes urbanos da cidade de Angicos-RN em um gradiente de ocupação urbana, de acordo com o CONAMA 357/05. Os parâmetros físico-químicos analisados, prezaram à qualidade do solo e da planta, sendo alguns destes a Condutividade Elétrica (CE), cloreto $\left(\mathrm{Cl}^{-}\right)$, sódio $\left(\mathrm{Na}^{+}\right)$, cálcio e magnésio $\left(\mathrm{Ca}^{2+} \mathrm{e} \mathrm{Mg}^{2+}\right)$; como também, a concentração demetais pesados, como o cobre $(\mathrm{Cu})$, cádmio $(\mathrm{Cd})$ e chumbo $(\mathrm{Pb}) . \mathrm{Na}$ análise do cobre, todos os açudes apresentaram concentrações maiores que o permitido $(0,009$ $\mathrm{mg} / \mathrm{L}$ ). O chumbo foi o metal pesado que registrou concentrações apenas para o açude José Teodoro sendo maior que o estabelecido pela legislação $(0,01 \mathrm{mg} / \mathrm{L})$. Assim, cada um dos açudes foi classificado com um nível de qualidade para o usona irrigação, sendo o açude Caraubinhas apresentando boas condições, o açude Novo Angicoscom qualidade média e o açude José Teodoro classificado como irregular.
\end{abstract}

Palavras-chave: Chumbo; Metais pesados; Reservatório de água; Semiárido.

\begin{abstract}
The municipality of Angicos is located in the semi-arid region of northeastern Brazil, where climatic conditions cause scarcity. Thus, this work aims to evaluate the quality of water for irrigation of the three urban reservoirs in the city of Angicos-RN in an urban occupation gradient, according to CONAMA 357/05. The physical-chemical parameters analyzed focused on the quality of the soil and the plant, some of which were Electrical Conductivity (EC), chloride $(\mathrm{Cl}-)$, sodium $(\mathrm{Na}+)$, calcium and magnesium $(\mathrm{Ca} 2+$ and $\mathrm{Mg} 2+)$; as well as the concentration of heavy metals, such as copper $(\mathrm{Cu})$, cadmium $(\mathrm{Cd})$ and lead $(\mathrm{Pb})$. In the copper analysis, all the dams presented concentrations higher than the allowed $(0.009 \mathrm{mg} / \mathrm{L})$. Lead was the heavy metal that registered concentrations only for the José Teodoro reservoir, being higher than that established by legislation $(0.01 \mathrm{mg} / \mathrm{L})$. Thus, each of the reservoirs was classified with a quality level for use in irrigation, with the Caraubinhas reservoir showing good conditions, the Novo Angicos reservoir with average quality and the José Teodoro reservoir classified as irregular.
\end{abstract}

\footnotetext{
${ }^{1}$ Universidade Federal Rural do Semi-árido.

*E-mail: franciscosouto@ufersa.edu.br
} 
Keywords: Lead; Heavy metals; Water tank; Semiarid.

\section{INTRODUÇÃO}

Com o pequeno volume de água doce no planeta (cerca de 3\%, sendo apenas uma pequena parcela disponível para o ser humano), o Brasil é o país mais privilegiado, com $12 \%$ da água doce mundial distribuída entre rios, açudes e barragens (A IMPORTÂNCIA DA ÁGUA, 2013). Apesar de sua importância, estes locais são os principais alvos de poluição. Em2017, a Agência Nacional das Águas (ANA) realizou uma pesquisa e constatou que $81 \%$ dos municípios brasileiros despejam pelo menos $50 \%$ do esgoto que produzem diretamente em cursos de água próximos, sem submeter a nenhum tratamento (COSTA, 2017).

A Organização Mundial de Saúde (OMS) revelou em 2011 que pelo menos 2 milhões de pessoas morrem, a cada ano, em decorrência de doenças que estão vinculadas ao uso da água(OMS, 2011). Isso tem se agravado devido ao aumento da poluição e a falta de uma legislaçãomais rigorosa que esteja presente de forma efetiva nos municípios brasileiros.

É necessário ressaltar que em Angicos há evidências de poluição nos mananciais de águas presente em área urbana, como é o caso de reservatórios da cidade de Toledo-PR, que tem situações parecidas com a de Angicos (ENDLER et $a l ., 2013)$. Estes reservatórios se fazemmuito presente na vida da população, onde parte da alimentação animal e vegetal da comunidade é irrigada com a água destes açudes, principalmente no período de seca. Com isso,o cuidado que se deve ter com as reservas hídricas é importante, pois a disponibilidade da água diminui gradativamente, sobretudo no semiárido, devido ao baixo índice pluviométrico, distribuição irregular de chuvas ao longo do ano, intensa evapotranspiração e a degradação domeio ambiente.

Diante do exposto justifica-se a realização do presente trabalho com o objetivo de avaliar a qualidade da água dos açudes: Caraubinhas, José Teodoro e Novo Angicos para fins de irrigação em propriedades urbanas do município de Angicos, no Estado do Rio Grande do Norte. 


\section{FUNDAMENTAÇÃO TEÓRICA}

\section{Qualidade de água para irrigação}

Devido à grande crise hídrica na região nordeste, o Rio Grande do Norte é um dos Estados do semiárido que dispõe de vários reservatórios de água, conhecido localmente por açudes, no intuito de diminuir as consequências da seca. Contudo, a contaminação presente em grande parte desses reservatórios, devido à má administração, implica em resultados desfavoráveis no que se refere à economia e a saúde. Segundo Viviane Amaral (doutora em genética e biologia molecular pela Universidade Federal do Rio Grande do Norte), esse problema vai além, “A perda da qualidade de água do açude, além de se tratar de um problemaambiental, é também um problema social, já que a saúde e a economia da comunidade são diretamente afetadas.” (PORTAL DE MEIO AMBIENTE DA UFRN, 2017).

Além da degradação dos corpos d'água, influenciada pela grande quantidade de poluição humana existente, assim como uma crescente demanda desfavorecida pela quantidadelimitada de água, se tem pouco investimento que possibilite o desenvolvimento de pesquisas e atividade de monitoramento que melhorem a qualidade do pequeno volume de água existente (CHAVES, 2014). Mesmo sabendo que a qualidade da água é um aspecto fundamental para o êxito da utilização de sistemas irrigados, a avaliação da qualidade dela é, muitas vezes, negligenciada no momento da elaboração de projetos. Como consequência, a irrigação poderáproduzir efeitos indesejáveis na condução de uma cultura comercial ou servir como veículo para contaminação da população, no momento em que ocorre a ingestão dos alimentos que receberam a água contaminada (PEREIRA et al., 1992).

Indicadores de qualidade para irrigação

Devido aos grandes índices de poluição existentes nos mananciais, a qualidade da águamuitas vezes é mais importante a que a quantidade, uma vez que, uma água de má qualidade pode prejudicar o resultado final do processo, mesmo em pequenas proporções. Entretanto, a qualidade de água para irrigação nem sempre é definida com perfeição, pois o seu contato como solo, a vegetação e o manejo implicará em resultados variáveis, que precisarão ser compensados com o controle e a qualidade da água utilizada (SILVA et al., 2011). 
Os aspectos fundamentais a considerar no uso da água para irrigação são aqueles que afetam principalmente a conservação do solo e o rendimento da qualidade das colheitas. Dentreestes se encontram o critério de salinidade, sodicidade, toxidade e outros (ALMEIDA, 2010; AYERS; WESTCOT, 1991).

Em relação a salinidade, o parâmetro avaliado é a Condutividade Elétrica (CE), que determina a quantidade total de sais dissolvidos em água, indicando a maior/menor facilidade com que a corrente elétrica atravessa uma solução. Os resultados são expressos pelo Sistema Internacional de Unidades (SI), em deciSiemens por metro (dS/m) (ALMEIDA, 2010).

A sodicidade é avaliada pela Razão de Adsorção de Sódio (RAS), que revela aproporção relativa em que se encontra o sódio $\left(\mathbf{N a}^{+}\right)$em relação com o cálcio $\left(\mathbf{C a}^{2+}\right)$ e o magnésio $\left(\mathbf{M g}^{2+}\right)$, que são cátions bivalentes que competem com o sódio pelos lugares de intercâmbio do solo. A RAS é um parâmetro geral, uma vez que ele não leva em conta a relaçãoentre os compostos presentes na água e as fases sólidas ou líquidas do solo, de modo que, durante o processo de irrigação uma parte do sódio se dissolverá, ou precipitará, em carbonatosalcalinos terrosos quando for adicionada a ele, podendo ser concentrado ou manter-se em novosequilíbrios; e de outra, serão produzidos etapas de meteorizarão dos minerais, resultando na liberação de cátions à dissolução do solo. Além disso, a dureza é outro índice que está dentro da análise de sodicidade. Águas que apresentam uma alta dureza possuem grandes quantidades de cálcio e magnésio, usada principalmente para recuperar solos com alto teor de sódio. Os resultados para dureza são expressos em Graus Hidrométricos Franceses (GHF) (ALMEIDA, 2010).

A toxidade é um problema interno causado nas plantas devido a presença de íons

acumulados nas folhas através da transpiração, podendo ser altamente prejudicial. Muitas vezesesse fato é promovido por meio da irrigação, seja ela por superfície ou por aspersão, com algumas substâncias que mesmo em baixas concentrações oferecem riscos aos vegetais. Os principais íons que são responsáveis por isso, são o cloreto $\left(\mathbf{C l}^{-}\right)$e o sódio $\left(\mathbf{N a}^{+}\right)$, expressos em mmolc/L (BOSO; GABRIEL; PIAZENTIN, 2016). 
O Potencial hidrogeniônico $(\mathrm{pH})$ é uma propriedade química que indica o nível de acidez e alcalinidade da água. A alteração no valor do pH se dá, na maioria das vezes, pelas águas com níveis de salinidade muito baixo (AYERS; WESTCOT, 1991). O pH também influencia, juntamente com o gás carbônico dissolvido, a quantidade relativa de íons carbonato $\left(\mathrm{CO}_{3}{ }^{2-}\right)$. Em águas doces a quantidade destes íons é inferior aos íons bicarbonato, devido ao $\mathrm{pH}$ do meio ser menor que 10 (geralmente). O íon carbonato não é aceitável em águas destinadasà irrigação, pois na forma de carbonato de sódio $\left(\mathrm{Na}_{2} \mathrm{CO}_{3}\right)$ é altamente tóxico para as plantase além disso, pode causar incrustações nas paredes das tubulações (LIMA; LOPES; LIMA, 2014).

$\mathrm{O}$ íon bicarbonato $\left(\mathrm{HCO}_{3}{ }^{-}\right)$não oxida e nem reduz em águas naturais, porém pode precipitar facilmente como carbonato de cálcio $\mathbf{C a C O}_{3}$ (em altas temperaturas), que emdeterminadas concentrações são essenciais para o solo, usados para regular os teores de cálcioe magnésio, diminuir os efeitos tóxicos do manganês e o mais importante, adequar o $\mathrm{pH}$ da solução para o solo, para que as raízes possam absorver os nutrientes de forma eficaz (LIMA; LOPES; LIMA, 2014; FIDA, 2018). Tanto o carbonato como o bicarbonato são expressos em mmolc/L.

Assim como qualquer elemento químico, alguns metais são importantes para o desenvolvimento das plantas, porém, alguns deles, mesmo em pequenas quantidades, podem causar prejuízos não só a agricultura (como a degradação do solo), mas também a saúde humana e animal. Todos estes são expressos em miligramas por litro (mg/L) (RAMALHO et al., 1998).

\section{MATERIAIS E MÉTODOS}

\section{Local de estudo}

O estudo foi realizado na cidade de Angicos (Rio Grande do Norte), localizada na Mesorregião Central Potiguar, entre as coordenadas 5³9’ de altitude Sul e $36^{\circ} 36^{\prime}$ de longitudeOeste, a aproximadamente $110 \mathrm{~m}$ de altitude em relação ao nível do mar. O município encontra-se entre as cidades de Fernando Pedroza (sul) e Itajá (sul e oeste), na Br 304, em uma área territorial de 741,6 Km² (IBGE, 2017). 
Figura 1. Localização de Angicos no mapa do Rio Grande do Norte.

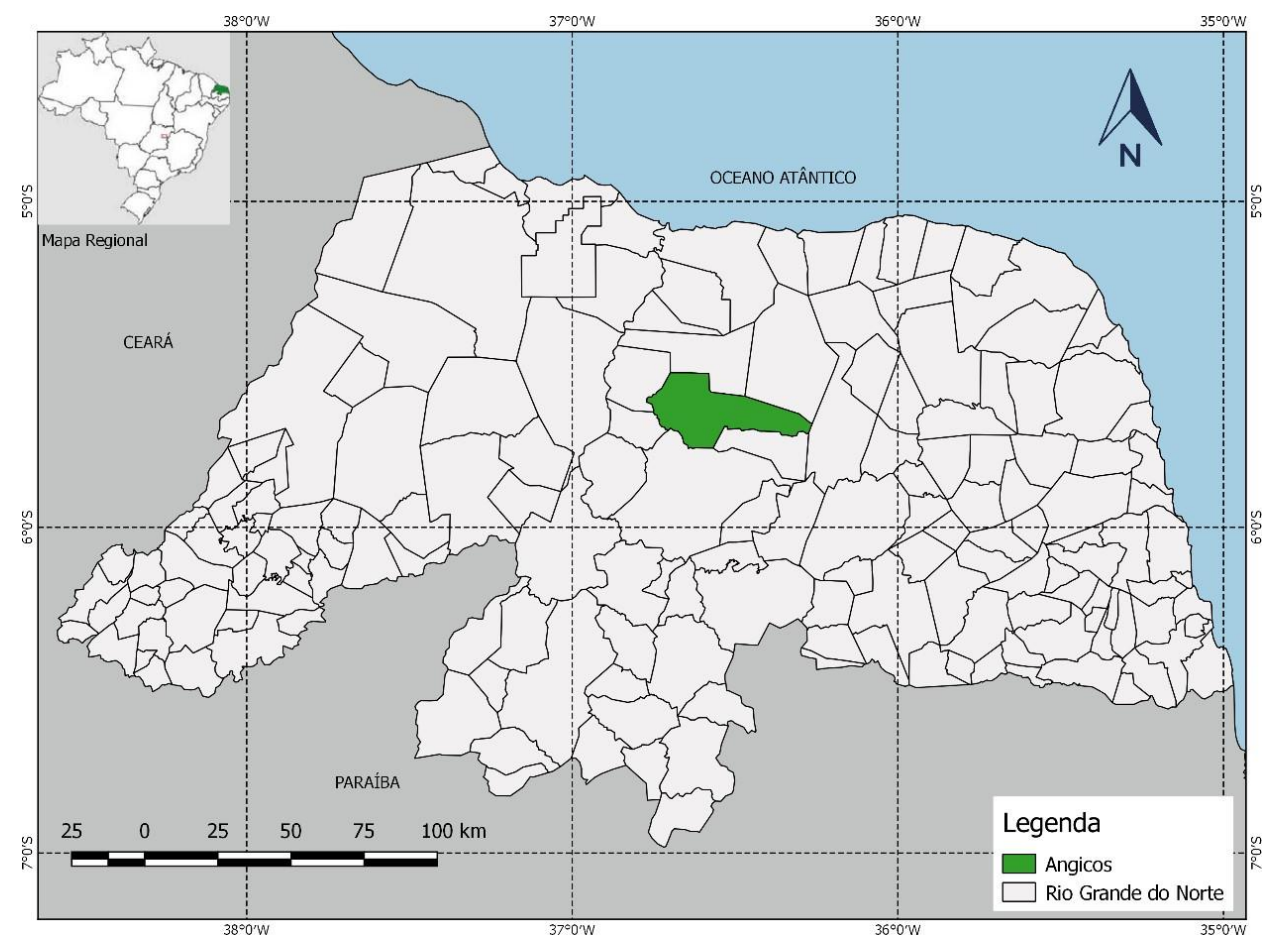

Fonte: Autoria própria (2019)

As condições climáticas são bastante estáveis na região, tendo sua maior parte do ano em períodos de seca. Seu clima semiárido favorece este aspecto, com uma temperatura média de $27,2^{\circ} \mathrm{C}$ (IDEMA, 2008), onde ocorre duas estações climáticas bem definidas, uma chuvosa,entre os meses de janeiro a maio, e outra seca, entre julho e dezembro (EMPARN, 2017).

Para exemplificar a pouca incidência de chuva, em 2018 foi registrado uma média de 583,7 mm, com menor precipitação entre os meses de junho e novembro, sem registrar nenhumaincidência de chuva, e maior entre março e abril, 99,6 e 184,1 mm, segundo os dados obtido pela Empresa de Pesquisa Agropecuária do Rio Grande do Norte (EMPARN) (EMPARN,2017). 


\section{Mapeamento}

Para o desenvolvimento deste trabalho, os limites geográficos de cada açude foram divididos em três pontos estratégicos de coleta (Figura 2), de modo que resultasse em uma análise geral da água contida em cada um deles. A definição destes pontos foi especificada da seguinte maneira: Ponto 1 (região mais rasa), Ponto 2 (região próximo das bombas de coleta) ePonto 3 (local próximo das mediações das paredes que represam a água). As coordenadas de cada ponto estão presentes na Tabela 1.

Tabela 1: Coordenadas dos pontos de coleta dos açudes Caraubinhas, José Teodoro e

Novo

Angicos.

\begin{tabular}{|c|c|c|c|c|}
\hline Pontos & Coordenadas & $\begin{array}{c}\text { Açude } \\
\text { Caraubinhas }\end{array}$ & $\begin{array}{c}\text { Açude José } \\
\text { Teodoro }\end{array}$ & $\begin{array}{c}\text { Açude Novo } \\
\text { Angicos }\end{array}$ \\
\hline \multirow{2}{*}{ P1 } & Latitude & $5^{\circ} 40^{\prime} 35.80^{\prime \prime S}$ & $5^{\circ} 40^{\prime} 5.07 " \mathrm{~S}$ & $5^{\circ} 39^{\prime} 53.64^{\prime \prime S}$ \\
\hline & Longitude & $36^{\circ} 35^{\prime} 42.05^{\prime \prime O}$ & $36^{\circ} 36^{\prime} 10.91 " \mathrm{O}$ & $36^{\circ} 35^{\prime} 2.90^{\prime \prime O}$ \\
\hline \multirow{2}{*}{$\mathrm{P} 2$} & Latitude & $5^{\circ} 40^{\prime} 29.30^{\prime \prime S}$ & $5^{\circ} 40^{\prime} 2.15^{\prime \prime S}$ & $5^{\circ} 39^{\prime} 50.00^{\prime \prime S}$ \\
\hline & Longitude & $36^{\circ} 35^{\prime} 49.40^{\prime \prime} \mathrm{O}$ & $36^{\circ} 36^{\prime} 10.65^{\prime \prime O}$ & $36^{\circ} 35^{\prime} 25.00^{\prime \prime O}$ \\
\hline \multirow{2}{*}{ P3 } & Latitude & $5^{\circ} 40^{\prime} 21.66^{\prime S} \mathrm{~S}$ & $5^{\circ} 40^{\prime} 0.45^{\prime \prime S}$ & $5^{\circ} 39^{\prime} 47.00^{\prime \prime S}$ \\
\hline & Longitude & $36^{\circ} 35^{\prime} 52.03^{\prime \prime} \mathrm{O}$ & $36^{\circ} 36^{\prime} 10.02^{\prime \prime O}$ & $36^{\circ} 35^{\prime} 42.00^{\prime \prime O}$ \\
\hline
\end{tabular}

Fonte: Autoria própria (2019)

Vale destacar que as figuras representadas abaixo identificam os açudes no período de cheia, e não no final do período de estiagem. Portanto, quando foram realizadas as coletas as delimitações da água se encontravam em um volume menor a que é explicito na Figura 2. 
Figura 2: Mapeamento dos pontos de coleta dos açudes Caraubinhas, José Teodoro e

Novo

Angicos.

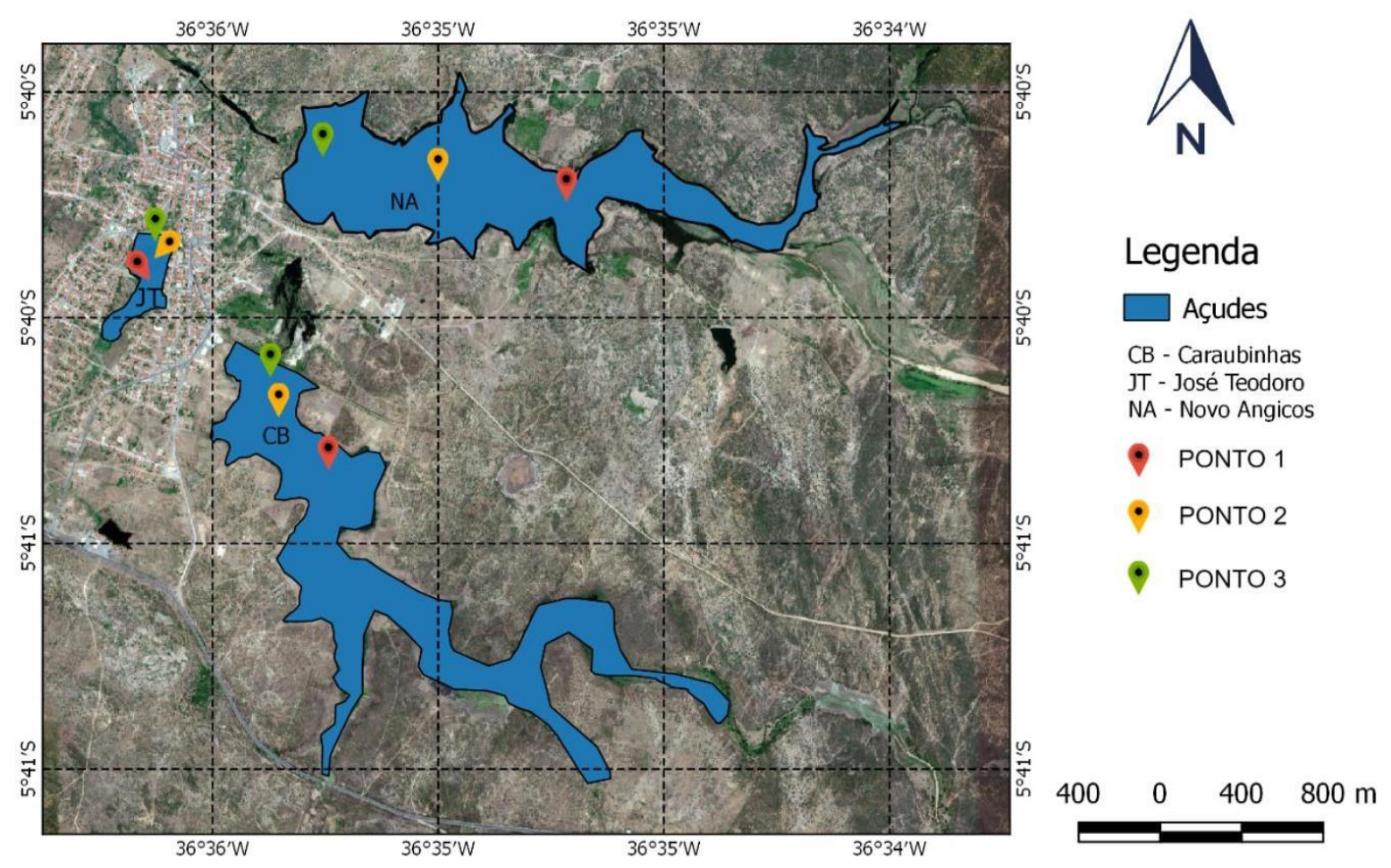

Fonte: Autoria própria (2019)

\section{Coleta}

As coletas de água foram feitas em dezembro de 2018 (final do período de estiagem), com garrafas plásticas de $500 \mathrm{~mL}$ submersas a uma profundidade de $15 \mathrm{~cm}$ abaixo da coluna deágua, separadas e identificadas (AYERS; WESTCOT, 1991). As amostras foram mantidas acondicionadas em uma caixa de isopor com gelo, e após a coleta foram armazenadas em geladeira a uma temperatura de aproximadamente $4^{\circ} \mathrm{C}$ (ALMEIDA, 2010), até o momento de realizar as análises no Laboratório de Solos, Água e Planta (LASAP), localizado na Universidade Federal Rural do Semiárido, em Mossoró-RN. 
Os dados de qualidade de água usados neste trabalho foram comparados com a CONAMA 357/05 (CONAMA, 2017), na resolução das águas destinadas a irrigação de culturas que o público venha a ter contato direto (como as cultivadas na comunidade), classificadas como classe II. Entretanto, apesar do Brasil não possuir uma legislação completa destinada a irrigação, foi tomado como base, além do CONAMA, outros trabalhos que determinaram as concentrações de diversas substâncias importantes, que por sua vez não estavam estabelecidos neste órgão, como: Condutividade Elétrica (CE), cloreto $\left(\mathrm{Cl}^{-}\right)$, sódio $\left(\mathrm{Na}^{+}\right)$, cálcio $\left(\mathrm{Ca}^{2+}\right)$ e magnésio $\left(\mathrm{Mg}^{2+}\right)$, cálcio $\left(\mathrm{Ca}^{2+}\right)$, carbonato $\left(\mathrm{CO}_{3}{ }^{2-}\right)$ e bicarbonato $\left(\mathrm{HCO}_{3}{ }^{-}\right)$. Os trabalhos que serviram de embasamento foram a Empresa Brasileira de Pesquisa Agropecuária (EMBRAPA)e a literatura de R. S. Ayers e D. W. Westcot, no livro A qualidade de água na agricultura (ALMEIDA, 2010; AYERS; WESTCOT, 1991).

\section{Análise de água}

Na LASAP, foram separados uma pequena quantidade de cada amostra em béqueres para análise do $\mathrm{pH}$, através do pHmetro de bancada digital modelo Íris-7 Tecnow. Na mesma quantidade em béqueres diferentes foram avaliados a $\mathrm{CE}$ para cada ponto por meio de um condutivímetro modelo Tec-4MP Tecnal.

$\mathrm{O} \mathrm{Na}^{+}$e $\mathrm{Ca}^{2+}$ foram analisados em um espectrofotômetro de chama, modelo DM-62 Digimed. Os outros metais foram analisados através de espectrometria de emissão ótica (ICP OES) modelo Optima DV 4300.

$\mathrm{O} \mathrm{Cl}^{-}$foi analisado por titulometria de precipitação (método de Mohr), titulado com nitrato de prata $\left(\mathrm{AgNO}_{3}\right)$ a $0,05 \mathrm{~mol} / \mathrm{L} ; \mathrm{CO}_{3}{ }^{2-}$ e $\mathrm{HCO}_{3}{ }^{-}$foram determinados por titulometria de neutralização, titulado com ácido sulfúrico $\left(\mathrm{H}_{2} \mathrm{SO}_{4}\right)$ a $0,5 \mathrm{~mol} / \mathrm{L}$; e o $\mathrm{Ca}^{2+}$ e $\mathrm{Mg}^{2+}$ foram determinados por titulometria de complexação, titulado com EDTA a 0,0125 mol/L. Seguindoo que é recomendado pelo manual de procedimentos de amostragem e análise físico-química de água (PARRON; MUNIZ; PEREIRA, 2011). 


\section{RESULTADOS E DISCUSSÕES}

As características das amostras de cada açude foram avaliadas a partir de análises laboratoriais descritas na Tabela 2, levando em consideração os parâmetros de $\mathrm{pH}, \mathrm{CE}, \mathbf{N a}^{+}, \mathbf{C a}^{2+}, \mathbf{M g}^{2+}, \mathbf{C l}^{-}, \mathbf{C O}_{3}{ }^{2^{-}}, \mathbf{H C O}_{3}{ }^{-}, \mathrm{RAS}$ e dureza.

Tabela 2. Resultado das análises físico-química (aspectos fundamentais) da água dosaçudes Caraubinhas, José Teodoro e Novo Angicos

\begin{tabular}{|c|c|c|c|c|c|c|c|c|c|c|}
\hline \multirow{2}{*}{ Análises } & \multicolumn{3}{|c|}{ Açude Caraubinhas } & \multicolumn{3}{|c|}{ Açude José Teodoro } & \multicolumn{3}{|c|}{ Açude Novo Angicos } & \multirow{2}{*}{ Unidade } \\
\hline & 1 & 2 & 3 & 1 & 2 & 3 & 1 & 2 & 3 & \\
\hline $\mathrm{pH}$ & 7,87 & 8,17 & 8,30 & 8,46 & 8,15 & 8,57 & 7,80 & 8,14 & 8,24 & - \\
\hline $\mathrm{CE}$ & 0,44 & 0,45 & 0,46 & 2,27 & 2,41 & 2,45 & 0,29 & 0,32 & 0,33 & $\mathrm{dS} / \mathrm{m}$ \\
\hline $\mathrm{Na}^{+}$ & 0,28 & 0,28 & 0,26 & 0,64 & 0,17 & 0,58 & 1,52 & 1,39 & 1,39 & mmolc/L \\
\hline $\mathrm{Ca}^{2+}$ & 1,36 & 1,35 & 1,15 & 2,52 & 2,37 & 2,23 & 1,34 & 1,22 & 1,17 & mmolc/L \\
\hline $\mathrm{Mg}^{2+}$ & 2,04 & 1,69 & 1,52 & 4,68 & 5,53 & 5,97 & 1,04 & 1,11 & 1,24 & $\mathrm{mmolc} / \mathrm{L}$ \\
\hline $\mathrm{Cl}^{-}$ & 1,40 & 1,60 & 1,60 & 10,60 & 11,00 & 11,00 & 1,60 & 1,60 & 1,60 & mmolc/L \\
\hline $\mathrm{CO}_{3}{ }^{2-}$ & 0,60 & 0,80 & 0,40 & 0,14 & 0,14 & 0,15 & 0,40 & 0,60 & 0,20 & mmolc/L \\
\hline $\mathrm{HCO}_{3}^{-}$ & 2,60 & 2,60 & 2,70 & 6,60 & 7,20 & 6,40 & 2,10 & 2,00 & 2,00 & $\mathrm{mmolc} / \mathrm{L}$ \\
\hline RAS & 0,20 & 0,20 & 0,20 & 0,30 & 0,10 & 0,30 & 1,40 & 1,30 & 1,30 & - \\
\hline Dureza & 15,93 & 14,16 & 12,46 & 32,98 & 37,53 & 39,10 & 10,90 & 10,73 & 11,16 & $\mathrm{mg} / \mathrm{L}$ \\
\hline
\end{tabular}

Fonte: Autoria propria (2019)

O pH para a o uso da irrigação possui um limite de 7,0 a 9,0 considerado normal (CONAMA, 1981). Os valores obtidos nas análises dos três açudes correspondem a este intervalo. O caráter básico dos açudes é devido à uma certa porcentagem de íons dissolvidos como o carbonato e bicarbonato, derivados do carbonato e bicarbonato de cálcio (AYERS; WESTCOT, 1991).

A salinidade, indicada pela CE, para os açudes Caraubinhas e Novo Angicos estiveramnormais, apresentando resultados menores que $0,7 \mathrm{dS} / \mathrm{m}$, considerado como nenhuma restriçãoao uso. Já o açude José Teodoro obteve valores maiores, no intervalo de 0,7 a 3,0 dS/m, contando com um grau de restrição médio, devendo se 
ter atenção na cultura empregada as que são cultivadas na cidade (como grãos, tuberculos, hortaliças) (ALMEIDA, 2010).

A avaliação da sodicidade, determinada pela RAS juntamente com a CE, demonstrou bons resultados. O intervalo para a RAS de 0 a 3 (estabelecido na norma) foi o resultado para os três açudes, que ao ser analisado junto a condutividade elétrica demonstrou uma restrição média para os açudes Caraubinhas e Novo Angicos, com valores de 0,7 a $0,2 \mathrm{dS} / \mathrm{m}$, e normal para o açude José Teodoro com valores maiores que $0,7 \mathrm{dS} / \mathrm{m}$. Altas concentrações de sódio reduzem a capacidade de infiltração da água no solo, impedindo das raízes absorverem os nutrientes (ALMEIDA, 2010; AYERS; WESTCOT, 1991).

Em relação a toxidade, os resultados foram positivos
para

$\mathrm{Na}^{+}$, tanto para a irrigação por superfície como por aspersão. As análises dos três açudes apresentaram valores menores que 3 (RAS) e 3 mmolc/L, que indica nenhuma restrição ao usoda irrigação por superfície e aspersão respectivamente. Os resultados para $\mathrm{o}^{-} \mathbf{C l}^{-}$foram normais para os açudes Caraubinhas e Novo Angicos, menor que 4 e 3 mmolc/L, emrelação a irrigação por superfície e por aspersão respectivamente, sem apresentar nenhuma restrição ao uso; já o açude José Teodoro foi verificado valores absurdos, maiores que 10 e $3 \mathrm{mmolc} / \mathrm{L}$, em relação a irrigação por superfície e por aspersão, respectivamente. Estes elementos em elevadas concentrações podem impedir a absorção de fósforo e nitrogênio para as plantas, assim como, diminuir a permeabilidade do solo e causar queimaduras nas folhas (ALMEIDA, 2010; AYERS; WESTCOT, 1991).

A dureza calculada pelo GHF para as amostras dos açudes Caraubinhas e Novo Angicos compreende o intervalo de 14 a $22 \mathrm{mg} / \mathrm{L}$, classificados como água mediamente doce. Já as amostras do açude José Teodoro apresentaram valores elevados, 32 a $54 \mathrm{mg} / \mathrm{L}$, possuindo umaágua dura para a irrigação (ALMEIDA, 2010).

Os valores para $\mathrm{O}_{\mathrm{HCO}_{3}}{ }^{-}$dos três açudes ficaram entre a faixa de 1,5 a 8,5 $\mathrm{mmolc} / \mathrm{L}$, que expressa um grau de restrição médio (ALMEIDA, 2010). Para o $\mathbf{C O}_{3} \mathbf{2}^{-}$os resultados foraminferiores ao $\mathbf{H C O}_{3}{ }^{-}$, uma vez que o $\mathrm{pH}$ das águas está classificado 
como normal. Porém, quando a soma das concentrações de ambos são maiores que a soma de $\mathbf{C a}^{2+}$ e $\mathbf{M g}^{2+}$, é calculado o Carbonato de Sódio Residual (CSR) como o valor em excesso de $\mathbf{C O}_{3}{ }^{{ }^{-}}$e $\mathbf{C O}_{3}{ }^{\mathbf{2}^{-}}$(ALMEIDA, 2010).

Segundo Almeida (2010), o excesso de CSR provoca a formação de carbonato e bicarbonato sódico, sais que provocam problemas aos solos por efeito do sódio, em especial ao

Na2Co3. Dessa forma, apenas os açudes Caraubinhas e Novo Angicos tiveram alguns pontos para serem calculados o CSR. Toda via, nenhum dos pontos apresentaram resultados superioresao estabelecido pela norma (1,25 mmolc/L) (ALMEIDA, 2010).

A tabela a seguir (Tabela 3) apresenta os resultados para os metais pesados a partir dosparâmetros de Al, Cr, Fe, Co, Cu, Cd, Mn, Ni, Zn, Ba e Pb.

Tabela 3. Resultado das análises dos metais pesados da água dos açudes Caraubinhas, José Teodoro e Novo Angicos

\begin{tabular}{|c|c|c|c|c|c|c|c|c|c|c|}
\hline \multirow{2}{*}{ Análises } & \multicolumn{3}{|c|}{ Açude Caraubinhas } & \multicolumn{3}{|c|}{ Açude José Teodoro } & \multicolumn{3}{|c|}{ Açude Novo Angicos } & \multirow{2}{*}{ Unidade } \\
\hline & 1 & 2 & 3 & 1 & 2 & 3 & 1 & 2 & 3 & \\
\hline $\mathrm{Al}$ & - & - & - & 0,255 & 0,253 & 0,254 & 0,007 & 0,003 & 0,008 & $\mathrm{mg} / \mathrm{L}$ \\
\hline $\mathrm{Fe}$ & 0,03 & 0,05 & 0,05 & 0,668 & 0,667 & 0,666 & 1,066 & 1,222 & 1,333 & $\mathrm{mg} / \mathrm{L}$ \\
\hline Co & 0,05 & 0,03 & - & 0,039 & 0,039 & 0,033 & 0,002 & 0,003 & 0,003 & $\mathrm{mg} / \mathrm{L}$ \\
\hline $\mathrm{Cu}$ & 0,02 & 0,03 & - & 0,266 & 0,276 & 0,277 & 0,017 & 0,016 & 0,017 & $\mathrm{mg} / \mathrm{L}$ \\
\hline $\mathrm{Cd}$ & - & - & - & 0,023 & 0,022 & 0,023 & 0,008 & 0,005 & 0,008 & $\mathrm{mg} / \mathrm{L}$ \\
\hline Mn & - & - & - & 0,242 & 0,244 & 0,241 & 0,015 & 0,012 & 0,013 & $\mathrm{mg} / \mathrm{L}$ \\
\hline $\mathrm{Ni}$ & - & - & - & 0,003 & 0,002 & 0,003 & - & - & - & $\mathrm{mg} / \mathrm{L}$ \\
\hline $\mathrm{Zn}$ & 0,01 & - & 0,01 & 0,344 & 0,333 & 0,331 & 0,618 & 0,666 & 0,658 & $\mathrm{mg} / \mathrm{L}$ \\
\hline $\mathrm{Ba}$ & - & - & - & 0,322 & 0,321 & 0,321 & - & - & - & $\mathrm{mg} / \mathrm{L}$ \\
\hline $\mathrm{Pb}$ & - & - & - & 0,233 & 0,222 & 0,222 & - & - & - & $\mathrm{mg} / \mathrm{L}$ \\
\hline
\end{tabular}

Fonte: Autoria própria (2019)

A concentração de alumínio (Al) para os açudes Caraubinhas (ausente de alumínio) e Novo Angicos apresentou resultados menores que 0,1 mg/L, encontrando-se dentro dos valores estabelecidos pela legislação. Já o açude José Teodoro obteve valores acima do estabelecido, apresentando intervalo de 0,253 a 
0,255 mg/L (CONAMA, 2017). Em solos com pH maior que 7 o alumínio precipita e elimina a toxidade, podendo atuar como um agente positivo para as plantas (ALMEIDA, 2010).

Apenas o açude Caraubinhas obteve resultados dentro da norma na concentração de ferro $(\mathrm{Fe})$, menor que $0,3 \mathrm{mg} / \mathrm{L}$, os demais tiveram resultados superiores. $\mathrm{O}$ açude que apresentou maiores concentrações foi o açude Novo Angicos, em uma faixa de 1,066 a 1,333 mg/L (CONAMA, 2017). Altas concentrações de ferro podem ser tóxicas para o plantio, principalmente quando o solo não tem boa aeração, como é o caso da cidade de Angicos. Outraconsequência que pode acontecer é o deposito branco nas folhas (ALMEIDA, 2010).

$\mathrm{Na}$ análise do cobre $(\mathrm{Cu})$, todos os açudes constataram concentrações maiores que o permitido $0,009 \mathrm{mg} / \mathrm{L}$, sendo o açude José Teodoro com valores bem maiores em relação aos outros (CONAMA, 2017). Em concentrações muito elevadas o cobre pode se tornar tóxico paraas plantas em solução nutritiva (ALMEIDA, 2010).

Os resultados da análise do cádmio $(\mathrm{Cd})$ se mostraram ausente para o açude Caraubinhas. Para os açudes Novo Angicos e José Teodoro as concentrações foram maiores doque 0,001 mg/L, estabelecido pela legislação (CONAMA, 2017). Baixas concentrações são estabelecidas para este metal devido a sua capacidade de acumulação potencial em solos e plantas, tornando prejudiciais, também, para o ser humano (ALMEIDA, 2010).

Para o manganês $(\mathrm{Mn})$, os açudes Caraubinhas e Novo Angicos tiveram resultados satisfatórios, sendo menores que o estabelecido pela legislação $(0,2 \mathrm{mg} / \mathrm{L})$. O açude José Teodoro obteve concentrações maiores, em um intervalo de 0,241 a 0,244 mg/L. O manganês pode se tornar tóxico mesmo em pequenas concentrações, porém, isso só ocorre em solos ácidos(ALMEIDA, 2010).

A concentração de chumbo $(\mathrm{Pb})$ foi constatada apenas no açude José Teodoro, mas aindacom valores que superam o limite estabelecido (maiores que 0,01 mg/L) (CONAMA, 2017). Ochumbo é um metal pesado altamente tóxico que interfere nas propriedades celulares das plantas em concentrações maiores que o permitido. Além disso, é prejudicial à saúde humanapela sua capacidade de acumulação 
potencial, assim como o cádmio (ALMEIDA, 2010). Os outros metais, Co, Ni, Zn e $\mathrm{Ba}$, estão todos dentro do limite estabelecido pela normapara as águas dos três açudes.

\section{CONCLUSÕES}

Para os parâmetros analisados, os açudes Caraubinhas e Novo Angicos evidenciaramboa qualidade de água, revelando em quase todas as análises resultados dentro da norma. Valedestacar aqui as concentrações de cádmio e ferro dissolvido acima do normal para o açude NovoAngicos, assim como, a alta concentração de cobre para o açude Caraubinhas. Estes parâmetrosprecisam de uma maior atenção, uma vez que se trata de substâncias tóxicas, podendo estáassociados ao descarte irregular de substâncias, como pilhas e baterias. Entretanto, o açude Caraubinhas foi o que apresentou melhores condições para irrigação entre os três açudes, apresentando boa qualidade, em seguida o açude Novo Angicos, com grau de restrição médio.

O Açude José Teodoro foi o que apresentou os maiores índices de rejeições referente aos níveis máximos da concentração permitida. Em quase todos os aspectos foram superiores, com ex̧̧eção do $\mathrm{pH}, \mathbf{H C O}^{-}, \mathrm{CSR}, \mathrm{Co}, \mathrm{Ni}, \mathrm{Zn}$ e Ba, com restrições normais ou médias. Os outrosparâmetros estiveram todos acima do normal, como é o caso dos metais que são altamente prejudiciais, com fatores tóxicos às plantas $\left(\mathrm{Na}^{+}\right.$, $\mathrm{Cl}^{-}, \mathrm{Fe}, \mathrm{Cu}, \mathrm{Ca}$ e $\mathrm{Pb}$ ) provocando deficiênciaem nutrição, queimaduras as plantas, impermeabilidade do solo e interferência nas propriedadescelulares (especialmente para o cádmio e o chumbo). Implicando, assim, em uma água imprópria para utilização na irrigação.

\section{REFERÊNCIAS}

A IMPORTÂNCIA DA ÁGUA. Brasil das Águas, 2013. Disponivel em: <http://brasildasaguas.com.br/equipes/operacional/>. Acesso em: 02 nov. 2018.

ALMEIDA , O. Á. D. Qualidade da água de irrigação. Embrapa: Mandioca e Fruticultura.Cruz das Almas, p. 227. 2010.

AYERS, R. S.; WESTCOT, D. W. A qualidade da água na agricultura. Campina Grande:UFPB, 1991. 218 p. (TRADUÇÃO). 
BOSO, C. M. R.; GABRIEL, P. C.; PIAZENTIN, J.. Análise dos parâmetros da qualidade daágua destinada a irrigação. Fórum Ambiental da Alta Paulista, São Paulo, 2016. p. 8.

CHAVES, L. C. C. influência da radiação ionizante natural no açude do boqueirão (RN):avaliação de risco saúde/ambiente. Universidade Federal do Rio Grande do Norte. natal- RN, p. 73. 2014.

CONAMA. Ministério do Meio Ambiente, 1981. Disponivel em: <http://www2.mma.gov.br/port/conama/estr1.cfm>. Acesso em: 13 novembro 2018.

COSTA, C. News Brasil. British Broadcasting Corporation (BBC), 2017. Disponivel em: 〈https://www.bbc.com/portuguese/brasil-41369116>. Acesso em: 11 fev. 2019.

DICIONÁRIO AMBIENTAL. O eco, 2014. Disponivel em: <https://www.oeco.org.br/dicionario-ambiental/27961-o-que-e-o-conama/>. Acesso em: 11 nov. 2018.

EMPARN. monitoramento pluviométrico. Empresa de Pesquisa Agropecuária do Rio Grande do Norte, 2017. Disponivel em: <http://189.124.130.5:8181/monitoramento/monitoramento.php>. Acesso em: 05 nov. 2018.

ENDLER, D. T. K. et al. Avaliação da Qualidade da Água de Irrigação Utilizada emPropriedades Rurais do Município de Toledo-PR, Toledo-PR, 30 out. 2013. p. 7.

FIDA. A IMPORTÂNCIA DO CALCÁRIO AGRÍCOLA NO SOLO, 2018. Disponivel

em: <https://www.fida.com.br/a-importancia-do-calcario-agricola-no-solo/>. Acesso em: 20fev. 2019.

IBGE. Geociências. Instituto Brasileiro de Geografia e Estatística, 2007. Disponivel em:

<https://cidades.ibge.gov.br/brasil/rn/angicos/pesquisa/18/16459>. Acesso em: 09 nov. 2018.

IBGE. IBGE cidades. Instituto Brasileiro de Geografia e Estatística, 2017. Disponivel em: <https://cidades.ibge.gov.br/brasil/rn/angicos/panorama>. Acesso em: 31 jan. 2019.

IDEMA. Perfil do Seu Município. Instituto de Desenvolvimento Sustentável e Meio Ambiente do Rio Grande do Norte - IDEMA, 2008. Disponivel em:<http://adcon.rn.gov.br/ACERVO/idema/DOC/DOC000000000016661.PDF>. Acesso em: 20fev. 2019.

CONAMA. LEI No 9433/1997 - PNRH. Agência Nacional das Águas, 2017. Disponivel em:<http://www3.ana.gov.br/portal/ANA/todos-os-documentos-do-portal/documentos- 
sre/alocacao-de-agua/oficina-escassez-hidrica/legislacao-sobre-escassez-

hidrica/uniao/lei-no- 9433-1997-pnrh/view>. Acesso em: 12 novembro 2018.

LIMA, J. O. G. D.; LOPES, F. D. C. D. C.; LIMA, J. R. Hidroquímica do carbonato e bicarbonato: efeito na qualidade de águas subterrâneas em Crateús, Ceará, Brasil. Ambiente eÁgua - An Interdisciplinary Journal of Applied Science, Crateús-CE, 20 julho 2014.

OMS. governo do Brasil, 2011. Disponivel em: $<$ http://www.brasil.gov.br/noticias/saude/2011/07/oms-pelo-menos-2-milhoes-depessoas- morrem-por-ano-no-mundo-por-causa-de-agua-contaminada $>$. Acesso em: 03 nov. 2018.

PARRON, M.; MUNIZ, D. H. D. F.; PEREIRA, C. M. Manual de procedimentos de amostragem e análise físico-química de água. Embrapa (Empresa de Pequisa Agropecuária). Colombo-PR. 2011.

PEREIRA, F. A. M. et al. Qualidade de água para irrigação no Seridó-RN. CONGRESSONACIONAL DE IRRIGACAO E DRENAGEM, Natal, 1992. p. 543562.

PORTAL DE MEIO AMBIENTE DA UFRN. Meio Ambiente, 2017. Disponivel em: <http://www.meioambiente.ufrn.br/?p=40677>. Acesso em: 08 nov. 2018.

RAMALHO, F. G. P. et al. Acumulação de metais pesados pelo uso de insumos agrícolas na microbacia de Caetes, Paty do Alferes, RJ. Empresa Brasileira de Pesquisa Agropecuária -Embrapa, Paty do Alferes-RJ, junho 1998. 29.

ROCKMANN, R. Carta Capital. Da agricultura familiar vem a base da alimentação nacional, 2017. Disponivel em: <https://www.cartacapital.com.br/especiais/nordeste/daagricultura-familiar-vem-a-base-da-alimentacao-nacional>. Acesso em: 09 nov. 2018.

SILVA, Í. N. et al. Qualidade de Água na Irrigação. ACSA - Agropecuária Científica noSemi-Árido, Patos-PB, v. 07, p. 15, 03 julho/setembro, 2011. 